\title{
Utilización de líquenes como adornos navideños en la región de Xalapa, Veracruz, México.
}

Uses of lichens in christmas festivities in Xalapa, Veracruz, México

Guzmán-Guillermo, ${ }^{1 凶}$, Barrera-Bernal, C. ${ }^{1,}$ Cárdenas-Mendoza, K.D.R. ${ }^{1}$

${ }^{1}$ Facultad de Biología de la Universidad Veracruzana Campus Xalapa ${ }^{1}$

${ }^{\bowtie}$ Autor para correspondencia: qwerty.guzmi@gmail.com

Recibido: $15 / 04 / 2019$

Aceptado: 15/05/2019

\section{RESUMEN}

La comercialización de los líquenes con diferentes finalidades es poco frecuente en el territorio mexicano. Para Veracruz, este es el primer reporte de la venta de líquenes para usarlos como adornos navideños. Se muestrearon 3 mercados ambulantes y 4 mercados fijos encontrándose que solo en dos ambulantes y en uno fijo se realiza la comercialización directa de líquenes. Además, se muestran los resultados de entrevistas semiestructuradas realizadas a los vendedores.

Palabras clave: Cladonia, Usnea, etnoliquenología, mercado.

\begin{abstract}
The commercialization of lichens is a rare occurrence in Mexico and this report is the first in Veracruz in which the sale of lichen as christmas ornaments is presented. Three itinerant and four fixed marked places were sampled, two from the former and one of the latter were found to participate in the sale of lichen. In addition, we provide the results from interviews with the lichen sellers.
\end{abstract}

Keywords: Cladonia, Usnea, Ethnolichenology, market place.

\section{INTRODUCCIÓN}

Los líquenes son organismos resultados de la interacción presumiblemente mutualista de varios simbiontes; hongos, algas y bacterias. Dentro de los ecosistemas cumplen distintas funciones ecológicas, como hábitat (Patterson et al, 1995), siendo parte de cadenas tróficas (Baur et al., 1994; Muller et al., 2011) y participando activamente en los ciclos biogeoquímicos (Coxson y Nadkarni, 1995).
En México se conocen alrededor de 2833 especies de hongos liquenizados, y la mayoría pertenecen a la división ascomycota (HerreraCampos et al., 2014). Sin embargo, el conocimiento real de la biodiversidad de este grupo está aún lejos de ser conocida en el país, pues existen estados, especialmente los del sur, prácticamente inexplorados. Así mismo, los estudios etnoliquenólogicos son escasos, y se reportan usos solamente de unos pocos líquenes en comparación con países europeos o asiáticos 
con una tradición etnoliquenológica documentada.

En municipios como el de Xalapa, en la región montañosa central de Veracruz, la diversidad de productos que podemos encontrar en los mercados locales es amplia, esto debido a que muchos recursos son obtenidos directamente del Bosque mesófilo de montaña y los Bosques templados existentes en la zona. Los productos extraídos de los bosques que destacan en estos mercados locales son el maquique, plantas de ornato (musgo, orquídeas, tigridias, sprekelias, etc.), especias, tejidos, leña, tierra de bosque, tintes, hongos comestibles y fauna diversa. A pesar de los estudios que se han venido realizando y los esfuerzos de distintos grupos académicos y gubernamentales por tratar de frenar la extracción de especies en alguna categoría de la NOM-059-2010-SEMARNAT, aún se observan, en estos establecimientos en el municipio de Xalapa, especies en riesgo de flora y fauna endémicas de la región.

Por otro lado, poco se sabe del estado de conservación de las especies liquénicas en México. En países como Canadá y algunos europeos, los líquenes son considerados prioritarios en sus estrategias de manejo forestal.

Además, poseen un amplio conocimiento del comportamiento bioindicador de muchas de sus especies. Así mismo, esos países conocen el estado de conservación de especies liquénicas y algunas de estas están protegidas. Caso contrario a México cuya NOM-059SEMARNAT-2010 no incluye en su listado a ningún hongo liquenizado. Con la finalidad de conocer los líquenes comercializados, es que se realiza este primer muestreo de líquenes en los mercados de Xalapa, Veracruz, México.

\section{MATERIALES Y MÉTODO}

Se realizaron visitas periódicas a mercados ambulantes y fijos de Xalapa, durante los meses de noviembre y diciembre del año 2018, con la intención de encontrar establecimientos donde se realizara la comercialización directa o indirecta de líquenes. Cuando se encontraron establecimientos cuyos productos contenían líquenes de manera intencional, se prosiguió a realizar una entrevista semiestructurada al comerciante. Esto último con la finalidad de obtener información sobre la procedencia del producto, valor comercial y los usos que les atribuyen.

Los organismos recolectados en los mercados se guardaron en bolsas de papel y fueron trasportados al laboratorio de Calidad Ambiental de la Facultad de Biología de la Universidad Veracruzana para su herborización e identificación. Para determinar sus identidades taxonómicas se emplearon métodos convencionales de liquenología ilustrados por Brodo et al. (2001), y las claves de identificación de Brodo et al. (2016) y para especies de Cladoniaceae de Ahti (2001).

\section{RESULTADOS}

De los 3 mercados ambulantes y 4 fijos muestreados la presencia de productos liquénicos directos se presentó en tres establecimientos: Mercado Galeana, Mercado Jáuregui y mercado ambulante dominical de la calle Toluca. Se encontró la comercialización intencional de una mezcla de Cladia aggregata (Sw.) Nyl y Cladonia rangiferina (L.) Weber ex F.H. Wigg y de ramas de árboles con especies variadas principalmente del género Usnea.

La especie más abundante fue $C$. rangiferina. La especie $C$. aggregata es comercializada en 
cantidades bajas mezclada con $C$. rangiferina. La mezcla de ambos líquenes o de solo $C$. rangiferina es vendida por montones (200-
$250 \mathrm{~g}$ ) a cinco pesos mexicanos en el mercado Galena (Ver figura 1).

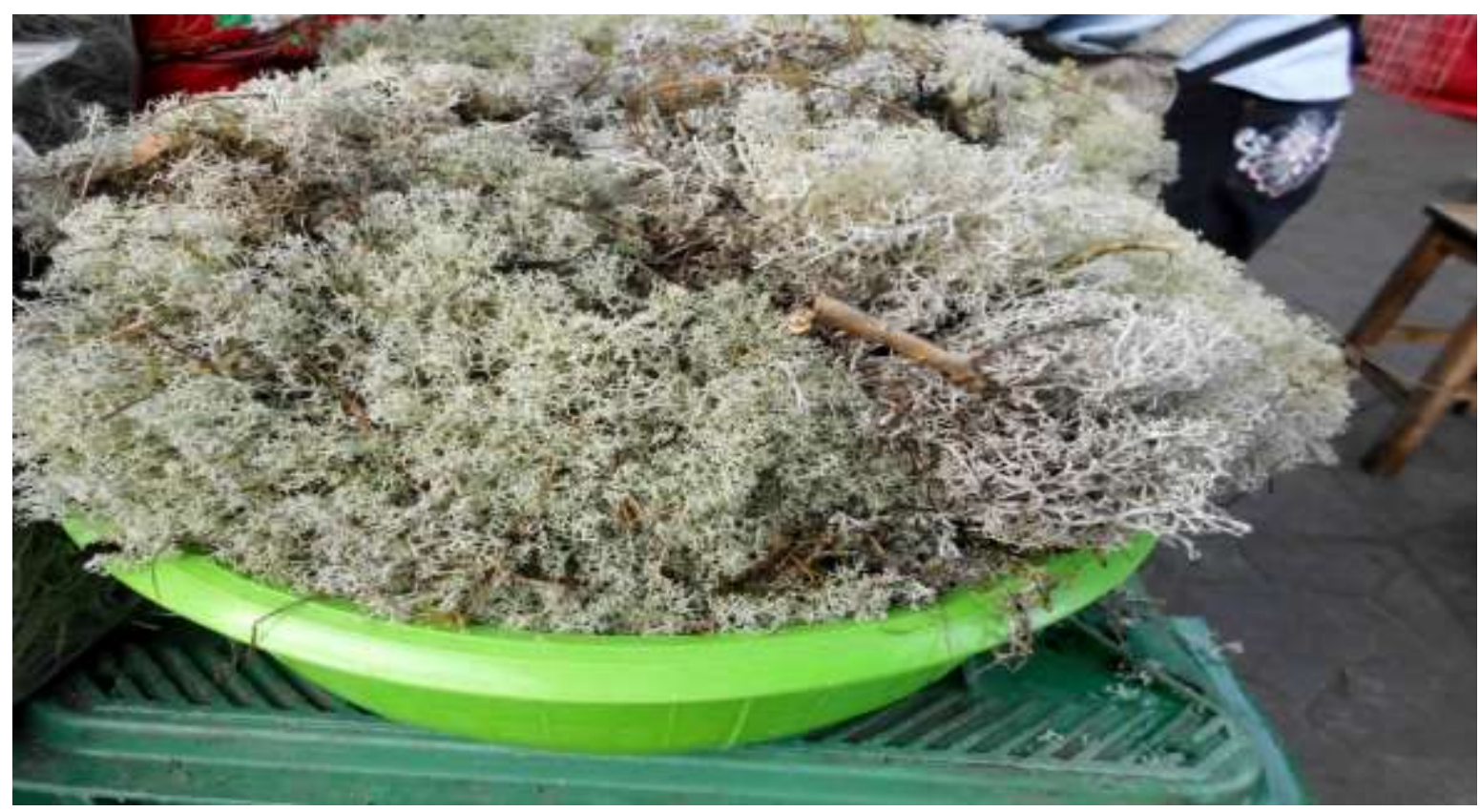

Figura 1. Cesto en el que se exhibe Cladonia rangiferina para su venta al público en el Mercado Galeana, en el municipio de Xalapa, Veracruz, México.

De la entrevista semiestructurada que se les realizó se obtuvo que: el nombre que los locales le asignan a la mezcla a de $C$. rangiferina y $C$. aggregata es "lama de piedra", "lama de piedra blanca" o "espuma de mar" y la utilización que le dan es únicamente decorativa como parte de las festividades decembrinas. Mencionaron que cada vez es más raro encontrar este liquen en los bosques “... ya casi no lo hay como en años anteriores...". Comentan que lo recolectan de “...las piedras que están en los bosques, en la tierra donde también hay pinos y en lugares cercanos a los arroyos, hacia las zonas boscosas..." de municipios vecinos.

Desafortunadamente no puntualizaron los puntos exactos de extracción aunque se sabe que está presente en bosques templados en las faldas del Cofre de Perote (Ver figura 2). Por otro lado, cabe hacer la puntualización de que dos comerciantes en el Mercado Jauregui mencionaron que "la venta de espuma de mar está prohibida". Sin embargo, a pesar de que esto debería ser así, no existe ninguna norma en México que regule la comercialización del liquen Cladonia rangiferina. 
Guzmán-Guillermo et al., 2019

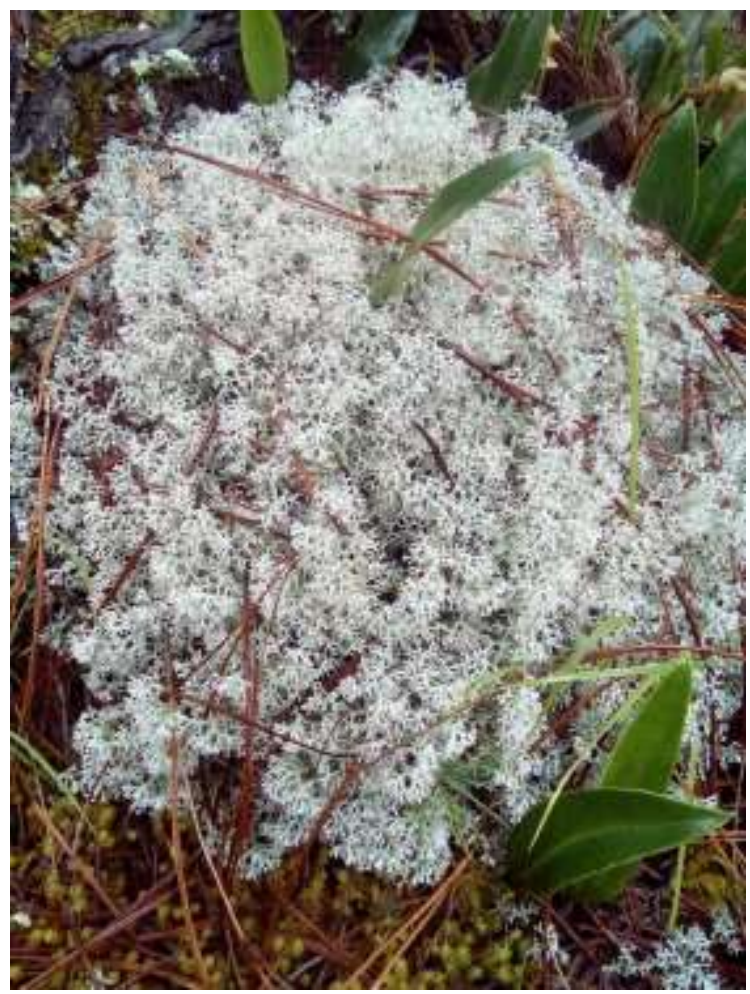

Figura 2. Cladonia rangiferina in situ en el El Volcancillo, municipio de Las Vigas, Veracruz. Foto: Gerón-Baez.

Por otro lado, las ramas de los árboles que venden como adornos navideños son del árbol llamado "escobillo" (ver figura 3). Ese árbol naturalmente posee cantidades altas de líquenes epifitos creciendo sobre sus ramas más externas y el principal propósito de venta de estas ramas es para ser colocadas sobre el "pinito de navidad", en los pesebres, como centros de mesa o en las puertas de las casas en épocas navideñas. La funga liquénica encontrada sobre las ramas que comercializan pertenecía a: Teloschistes flavicans, Heterodermia albicans,
Leucodermia leucomelos, L. boryi, Bryoria capillaris, Alectoria ochroleuca, Ramalina sp, Oropogon sp. y varias especies de Usnea; este último género es el más abundante en las ramas. El precio que alcanzan estas ramas varía de acuerdo con el tamaño $(40 \mathrm{~cm}$ a $1 \mathrm{~m})$ pero puede alcanzar hasta los cincuenta pesos mexicanos. El comerciante quiso puntualizar sobre la zona de extracción, solo mencionó provenir "del Cofre de Perote por arriba del municipio Coatepec". 


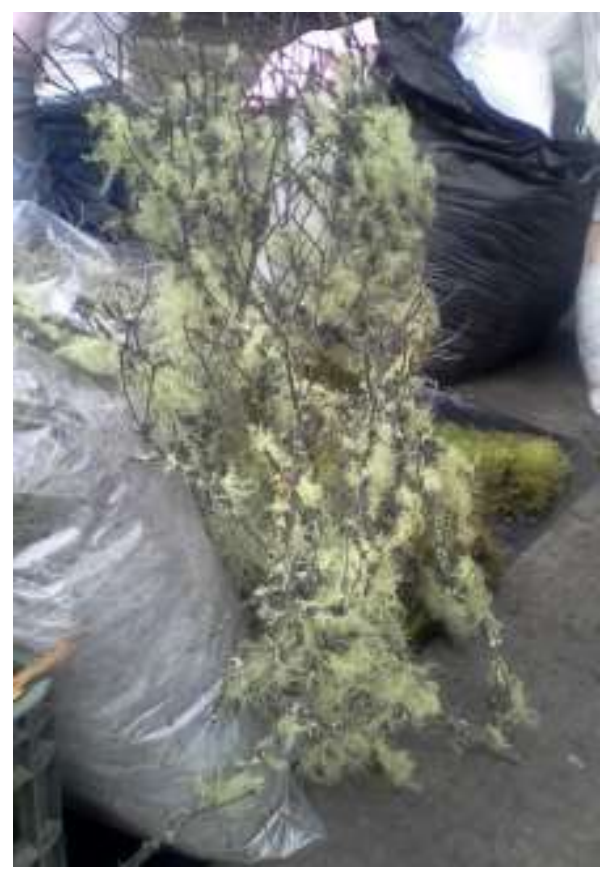

Figura 3. Ramas con líquenes en el mercado ambulante dominical de la calle Toluca del municipio de Xalapa, Veracruz, México.

Otros líquenes observados en todos los mercados fueron: Leucodermia leucomelos, Sticta fuliginosa y varias especies de los géneros Parmotrema, Peltigera, Polyblastidim y Physcia, los cuales se comercializan indirectamente en todos los mercados junto a la venta de musgo, con distintas finalidades: decoración navideña, abono para plantas o para retener la humedad en las macetas o bien como macetas ecológicas.

\section{DISCUSIÓN}

La comercialización de las especies $C$. aggregata y $C$. rangiferina se realiza únicamente en las temporadas decembrinas, pues su utilización está ligada específicamente con la tradición navideña. Los usuarios de este liquen lo utilizan para colocarlos en los pesebres navideños y como parte de las decoraciones propias de las épocas navideñas. La utilización de esta misma especie con la misma finalidad de decoración navideña, fue reportada anteriormente para Colombia y México (Ahti, 2001; Bautista-González, 2017), bajo el nombre de paxtle. Sin embargo, para la población de Xalapa, Veracruz, la palabra paxtle o paztle se refiere a Tillandsia usneoides.

Los estudios liquenométricos realizados para países boreales donde las temperaturas son considerablemente más bajas que las encontradas en los bosques templados de Veracruz, muestran que $C$. rangiferina muestra un periodo de regeneración de sus podecios en promedio de 6.9 años (Pegau, 1968). Para México se desconoce si algún mamífero u otro vertebrado se alimentan de alguno de estos líquenes y en general, las tasas de crecimiento de esta especie en nuestros ecosistemas.

Para otras regiones del país y en las zonas montañosas centrales de la Sierra de Zongolica, Veracruz, es conocido que algunos pobladores usan varias especies del género Usnea, con la 


\section{Guzmán-Guillermo et al., 2019}

intención de teñir sus tejidos de manera artesanal (Herrera-Campos et al., 2018; Contreras, 2015). Pero los usos de Usnea como parte de la decoración navideña aún no se documentaban para Veracruz.

Desafortunadamente, aunque existe la creencia de que las macetas realizadas de musgo y líquenes son amigables con el ambiente, esto realmente es falso y su utilización es nociva para los bosques, considerando el lento crecimiento de ambos grupos de organismos, además de que al ser retirados de los ecosistemas se impide el establecimiento de otros organismos y se priva de hábitat a insectos y de materiales para construcción de nidos de aves.

\section{CONCLUSIONES}

Los líquenes Usnea y Cladonia rangiferina son las únicas especies recolectadas, de los bosques aledaños al municipio de Xalapa, con intenciones reales de comercialización en épocas navideñas en Xalapa, Veracruz. Otros productos forestales no maderables como Tillandsia usneoides, conos de pinos y musgo, son comercializados en los mercados (ver Figura 4).

Es necesario y especialmente urgente continuar el estudio de los líquenes y la ecología de los mismos, en bosques templados de regiones montañosas de Veracruz.

Los trabajos que se realicen sobre las comunidades de esos organismos y sus interacciones ecológicas nos permitirán desarrollar mejores programas de manejo forestal y también regulación en la extracción tanto de recursos forestales maderables como aquellos no maderables.

\section{AGRADECIMIENTOS}

Al Laboratorio de Calidad Ambiental por su apoyo en la utilización de sus instalaciones durante la determinación de estos organismos. Así como al compañero estudiante de agronomía Rafael Gerón, por la facilitación de fotografías de Cladonia rangiferina in situ.

\section{LITERATURA CITADA}

Ahti, T. (2000). Cladoniaceae. Flora Neotropica Monograph 78, 1-362.

Bautista-González, J.A. (2017). Uso, conocimiento local y cosmovisión de líquenes en la región de TehuacánCuicatlán. Tesis de Maestría, Universidad Nacional Autónoma de México Instituto de Biología, Ciudad de México, México

Baur, A., Baur, B. y Fröberg, L. (1994). Herbivory on calcicolous lichens: different food preferences and growth rates in two co-existing land snails. Oecologia 98(3-4):313-319 https://doi.org/10.1007/BF00324219

Brodo, I. M., Duran Sharnoff, S., Sharnoff, S. (2001). Lichens of North America. Yale University Press 795 p. https://doi.org/10.29173/bluejay5827

Brodo, I.M. (2016). Keys to Lichens of North America. Yale University Press 427 p.

Contreras J., B. (2015). Reconocimiento del valor biocultural de la producción artesanal a través del intercambio de saberes: El caso de los textiles de lana en Tlaquilpa, Veracruz. Tesis de Maestría, Universidad Veracruzana Instituto de Ecología Tropical, Xalapa, Veracruz, México 
Coxson, D.S. y Nadkarni, N.M. (1995). Ecological roles of epiphytes in nutrient cycles of forest ecosystems. En: Lowman, M.D. y Nadkarni, N.M. Forest canopies. Academic, New York

Herrera-Campos, M.A., Lüking, R., PerezPerez, R.E., Miranda-Gonzales, R., Sanchez, N., Barcenas-Peña, A., Carrizos, A., Zambrano, A., Rhyan, B.D. y Nash, T.H. (2014). Diversidad de líquenes de México. Revista Mexicana de Biodiversidad 85:82-99 https://doi.org/10.7550/rmb.37003

Herrera-Campos, M.A., Falcón, L. y Falcón, T. (2018). Cuappachtli y Looxo xiae: El otro color de Usnea. Memorias del XII Congreso Nacional de Micología, Xalapa, Veracruz, México
Müller, C.E., Silva, A., Small, J., Williamson, M., Wang, X., Morris, A., Katz, S., Gamberg y Muir, D.C.G. (2011). Biomagnification of perfluirinated compouds in a remote terrestrial food chain: lichen-caribou-wolf. Environmental Science \& Technology 45(20):8665-8673 https://doi.org/10.1021/es201353v

Pattersson, R.B., Ball, J.P., Renhorn K.E., Esseen P.A. y Sjöberg, K. (1995). Invertebrate communities in boreal forest canopies as influenced by forestry and lichens with implications for passerine birds. Biological Conservation 74(1):5763.

https://doi.org/10.1016/0006-3207(95)000 $15-\mathrm{V}$

Pegau, R.E. (1968). Growth rates of important reindeer forage lichens on the Seward Peninsula, Alaska. Arctic 21: 255-259. https://doi.org/10.14430/arctic3268

Copyright (c) 2019 Jorge Guzm án-G uillermo, Clementina Barrera-Bernal yK. D. R. Cárdenas-Mendoza

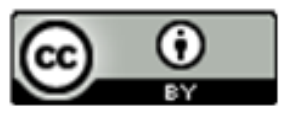

E ste tex to está protegido por una licencia CreativeCommons 4.0

Usted es libre para Compartir —copiar y redistribuir el $\mathrm{m}$ aterial en cualquier medio o formato-y Adaptar el documento -remezclar, transformar y crear a partir del material- para cualquier propósito, incluso para fines comerciales, siempre que cumpla la condición de:

Atribución: Usted debe dar crédito a la obra original de manera adecuada, proporcionar un enlace a la licencia, e in dicar si se han realizado cambios. Puede hacerlo en cualquier forma razonable, pero no de forma tal que sugiera que tiene el apoyo del licenciante o lo recibe por el uso que hace de la obra.

Resumendelicencia - Textocompletodelalicencia 